\title{
A Multidimensional Analysis of Pakistani Legal English
}

\author{
Samina Ali Asghar ${ }^{1}$, Muhammad Asim Mahmood ${ }^{2}$ \& Zobina Muhammad Asghar ${ }^{3}$ \\ ${ }^{1}$ University of Education (Lahore) Faisalabad Campus, Faisalabad, Pakistan \\ ${ }^{2}$ Government College University Faisalabad, Pakistan \\ ${ }^{3}$ Government Post Graduate College for Women, Mandi Bahauddin, Pakistan \\ Correspondence: Samina Ali Asghar, Department of English, University of Education, Faisalabad Campus near \\ Jawala Nagar Phatak College Road, Samanabad Faisalabad, Pakistan. E-mail: saminaali53@yahoo.com
}

Received: March 28, 2018 Accepted: May 26, 2018 Online Published: June 21, 2018

doi:10.5539/ijel.v8n5p215 URL: https://doi.org/10.5539/ijel.v8n5p215

\begin{abstract}
The present study aims to investigate linguistic variation among genres of Pakistani Legal English by applying multidimensional analysis. In a legal context, language performs different functions. This results in a variety of textual categories on the basis of purpose of communication and linguistic properties. In order to recognize the linguistic properties of any individual genre, a comparative study of genre categories is essential. The study has been conducted on the sample of eight Pakistani Legal genres based on around two million words. Data have been analyzed by applying Biber's (1988) model of Multidimensional analysis. Findings reveal variation in linguistic patterns. All categories have been found significantly different along each dimension. It indicates that legal language is not a homogeneous phenomenon. It has a variety of linguistic features associated with different legal genres, so it must be viewed in terms of goal, purpose, audience and context (variable which affect the language choice.).
\end{abstract}

Keywords: linguistic variation, multidimensional analysis, Pakistani Legal English

\section{Introduction}

Language, as a source of communication, is influenced by place, time, subject matter as well as situation of communication. It leads to variety of language choices and styles which provide a constant basis for research into different fields of language use i.e. medical, law etc. Variety of language activities are performed in legal contexts, for example, statutes, contracts between social members, appeals etc. Diversification of legal activities results into linguistic diversity.

Legal language which consists of a variety of legal discourses built around multiple written and oral genres, is classified by Danet (1985). This classification is based on two criteria: (1) the means of language use i.e. written or spoken. and (2) the level of formality, for example frozen, formal, consultative and casual etc. Documents like wills and contracts are in frozen written style, while statutes and briefs are examples of formal written style. Frozen spoken includes witnesses' oaths and marriage ceremonies whereas lawyer's questioning in court from witness is a type of formal spoken language. So far as casual spoken style is concerned, it involves lobby conferences and conversation between lawyers.

Variation in Legal language depends not only on the mode of language use (speech or writing), situation in which language is produced, participants, relationship between the participants, the purpose of communication, but also in its language patterns which can be comprehended if different genre categories are studied in comparison with reference to language characteristics.

Though legal discourse is a comprehensive term which involves a variety of legal discourses in both written and oral mode resulting into different text types (genre) (Maley, 1994; Trosborg, 1995 and Mattila, 2006), but previous studies on legal English in Pakistani context have dealt it as a homogenous phenomenon (Khan \& Khan, 2015; Ahmad, 2005). Register studies have emphasized that distribution of linguistic features is different across genres/registers. So, comparative analysis of these textual categories is required to comprehend linguistic properties of different genres. As no study in Pakistani legal context has been conducted in this regard, this study aims to analyze linguistic variation across legal genres in Pakistani context through multidimensional analysis. 


\subsection{Research Question}

1). To what extent do textual categories in Pakistani legal English differ across textual dimensions of 1988 model of variation?

\subsection{Significance of the Study}

As the study is aimed to identify linguistic variation among genres of Pakistani legal English, it will provide a comprehensive picture of Pakistani Legal English. The research will contribute to existing research on language variation in and across culture. The study will also be a significant addition in existing corpus based studies. Researchers working on discourse analysis may get help from the findings of the study. It will provide methodological framework for researchers. It will be a reference point for comparison with any special or nonspecial registers on the basis of results of 1988 MD. The findings of the study will be beneficial for ESP teachers to help them focusing on linguistic forms and their functions in particular genre. The findings of the study will be helpful for syllabus designers in order to decide content while dwelling upon linguistic features and their functions identified in this work.

The current research will prove to be of significant value to different researchers working on the registers of Pakistani English and the people working in establishing the identity of Pakistani English as a distinct non-native variety with its independent registers. Besides, it will be helpful for researchers conducting cross linguistic studies.

\section{Literature Review}

Legal language involves the type of language used in a legal setting. Tiersma (1999) defined legal language, "as the distinct manner of speaking and writing that has been developed by just about any legal system throughout the world". Danet (1985) asserted, "While language is central to all human affairs, it is particularly critical in the law. Physicians work with physical substances and entities; in contrast, the work of lawyers and judge is symbolic and abstract. In a most basic sense, law would not exist without language" (p. 273).

Legal English involves diverse oral and written genres based on their purpose of communication, the situation where they are used, participants, their relationships and the background knowledge of those who are engaged in activity of language use (Bhatia, 1987).

Tiersma (1999) acknowledged variation in legal language in his book "Legal Language" in these words, "It should be evident by now that there is great variation in legal language, depending on geographical location, degree of formality, speaking versus writing, and related factors. The language and style of lawyers also differ substantially from one genre of writing to another".

So, legal language is divided into different genres depending upon its use in different legal contexts i.e. different legislations, judgements, contracts, articles, textbooks, ordinances, appeals, wills, statutes, lawyers' counseling, witness examination, law statements produced by media reporters. This long list points out the multiplicity of legal discourse. Each category has distinctive terminology. Maley (1994) described that "There is not one legal discourse but a set of related legal discourses. Each has a characteristic flavour but each differs according to the situation in which it is used" (p. 13). Having acknowledged that legal discourse is manipulated in different legal contexts, Maley (1994) proposed different categories such as "judicial discourse, courtroom discourse, the language of legal documents (contracts, regulations, deeds, wills, statutes) the discourse of legal consultation" (p.13).

Tiersma (1999) asserted this idea by saying: Clearly, legal language is not monolithic. Even if we limit ourselves to the written variety, there is substantial variation among different genres of documents. Generally speaking, operative documents have by far the most legalese, as compared to persuasive and expository documents ( $\mathrm{p}$. 141).

In spite of the fact that legal language is diversified, many of the researchers have dealt it as monolithic phenomenon. A lot of work done in legal discourse focused on different facet of legal textuality (Palmer \& Pearce, 1983; Danet, 1983; Maley, 1994; Trosborg, 1995; Tiersma, 1999). Bhatia (1993) identified structural and lexico-grammatical features in different genres of legal discourse. Lundquist (1995) studied the functions of indefinite noun phrases in different legal categories i.e. textbooks, judgments, laws and legal articles. This study highlighted characteristics of different textual categories in regards to the use of indefinite noun phrases. Linguistic and pragmatic properties in English legal discourse were examined by Gotti $(2001,2008)$ whereas areas of semiotics, pragmatics and forensic linguistics were investigated by Jackson (1995), Trosborg (1997) and Gibbons (2004). 
These studies highlighted the importance of language variations reflected in different genre categories where law and language interface but their focus is single linguistic feature. Single linguistic feature does not help to understand any distinct variety in depth. Detailed picture of co-occurrence of linguistic patterns manifested in any category is essential. For this purpose, multidimensional analysis is a comprehensive methodology.

Brown and Fraser (1979) asserted the importance of co-occurring linguistic features in following words:

It is often difficult or even misleading to concentrate on specific, isolated [linguistic] markers without taking into account systematic variations which involve co-occurrence of sets of markers. A reasonable assumption is that socially significant linguistic variations occur normally as varieties or styles, and it is on those varieties that we should focus. (pp. 38-39)

In previous literature, two studies in American and Turkish contexts (i.e. Patterns of Linguistic Vaiation in Americann English by Roszkowski (2011) and A Comparative Register Perspective on Turkish Legislative Languag by Ozyildirim (2011)) focussed on linguistic variation in legal genres by applying multidimensional analysis. They identified markers of language use and language structures that vary from those found in other communication situations. So far as Pakistan is concerned, register studies other than legal register in English were conducted using Multidimensional analysis, for example a researcher (Shakir, 2013) identified linguistic variation across print advertisements in Pakistani media. In a study, linguistic variations across press reportage in Pakistani print media were investigated (Ahmad, 2015). In another study (Ali, 2016), linguistic patterns in Pakistani English Fiction were analyzed. Alvi (2016) studied linguistic variations in Pakistani press Editorials. But no study has yet been conducted to explain the way genres of Pakistani legal English are distinguished from one another based on sets of co-occurring linguistic features. So the present research focuses this aspect of Pakistani Legal English.

\section{Research Methodology}

This section describes the research methods applied to conduct this study. It includes nature of study, corpus design and data analysis procedure. This study is a blend of quantitative and qualitative methods. It provides a comprehensive linguistic description of Pakistani legal genres and calculates linguistic dimensions on the basis of co-occurring linguistic features.

\subsection{Corpus}

Corpus of Pakistani legal English has been chosen for this study. It covers the period of 2007-2014 and includes texts or categories of legal genres. The collection of texts comprises eight legal genres i.e. constitutions, directives, acts, articles, legal decisions, ordinances, legal reports and rules and regulations. The word range contains around two million words. The Pakistani Law Corpus has been borrowed from department of English linguistics Government College University Faisalabad. The legal genres related to written activities in Pakistani legal culture have been focused. All of them have been selected depending upon significance, accessibility and readerships.

\subsection{Data Analysis}

The current study examines differences and similarities among Pakistani legal genres by applying model of MD analysis proposed by Biber (1988) in his work "Variation across Speech and Writing". This model analyzes new discourse categories with respect to formerly determined dimensions (Biber, 1988) and is generally known as the 1988 MD model. It includes five dimensions i.e. "Involved vs. Informational Production", "Narrative vs. Non-narrative Concerns", "Explicit vs. Situation Dependent Reference", "Overt Expression of Persuasion", "Abstract vs. Non-Abstract Information". This model of variation is based on 67 linguistic variables classified into 16 main categories on the basis of grammar and function (Detail of the linguistic features underlying these categories can be seen in Biber (1988, pp. 223-245).

Analysis is based on following steps:

3.2.1 Tagging Lexical and Syntactic Features (Computational Identification of Linguistic Features) and Computing Frequencies of Linguistic Features

Data have been tagged through Biber's tagger. All linguistic features related to textual diemsnions of 1988 model of variation have been identified through this tagger. After tagging, frequencies of these features have been computed.

\subsubsection{Normalizing Frequencies}

Next to the computation of raw frequencies of linguistic features, is the step of normalizing frequencies. Frequencies of linguistic features have been normalized out of 1000 words in order to avoid error due to varying 
text lengths. Normalization makes comparison across texts possible. The significance of this process has been described by Biber (1988) in these words, "This normalization is crucial for any comparison of frequency counts across texts, because text length can vary widely" (p.75).

\subsubsection{Standardization of Frequencies of Linguistic Features}

After normalization, frequencies have been standardized to the mean of 0.0 and a standard deviation of 1.0 to give an equal weight to the linguistic features and make them comparable.

\subsubsection{Computing Dimension Scores}

Dimension scores for each text have been computed. This step involves sum total of standardized scores of positive features minus standardized scores of negative features. Dimensions with only positive features include only the sum of those features and vice versa.

3.2.5 Applying Analysis of Variance

Analysis of Variance has been applied to compare legal genres with one another.

\section{Results and Discussion}

This section is based on data analysis and discussion on results. The data have been analyzed by applying Biber's (1988) model of Multidimensional analysis. This model identifies five dimensions in each category of legal genre. Each dimension may or may not have two sets of co-occurring linguistic features, i.e. positive and negative.

Pakistani legal genres have been compared along each dimension (the mean dimension scores for Pakistani legal genres, minimum and maximum dimension scores, the range and the standard deviation have been displayed in Appendix). Excerpts from different categories have been provided to support the results.

\section{Dimension 1: Involved versus Informational Production}

Dimension one is a very powerful dimension as it consists of twenty four linguistic features including twenty one positive and three negative features. The features with negative weight indicate high information focus and the texts with integrated information (Conrad \& Biber, 2001, p. 24). On the contrary, linguistic features having positive loadings are: private verbs, that deletions, contractions, present verbs, second person pronouns, proverbs do, demonstrative pronouns, emphatics, first person pronouns, pronominal forms it, verb be, subordinating conjunction causatives, discourse particles, nominal pronouns, hedges, amplifiers, WH questions, possibility modals, coordinating conjunctions, WH clauses and final prepositions. These features are associated with interactional, involved and non-informational nature of texts.

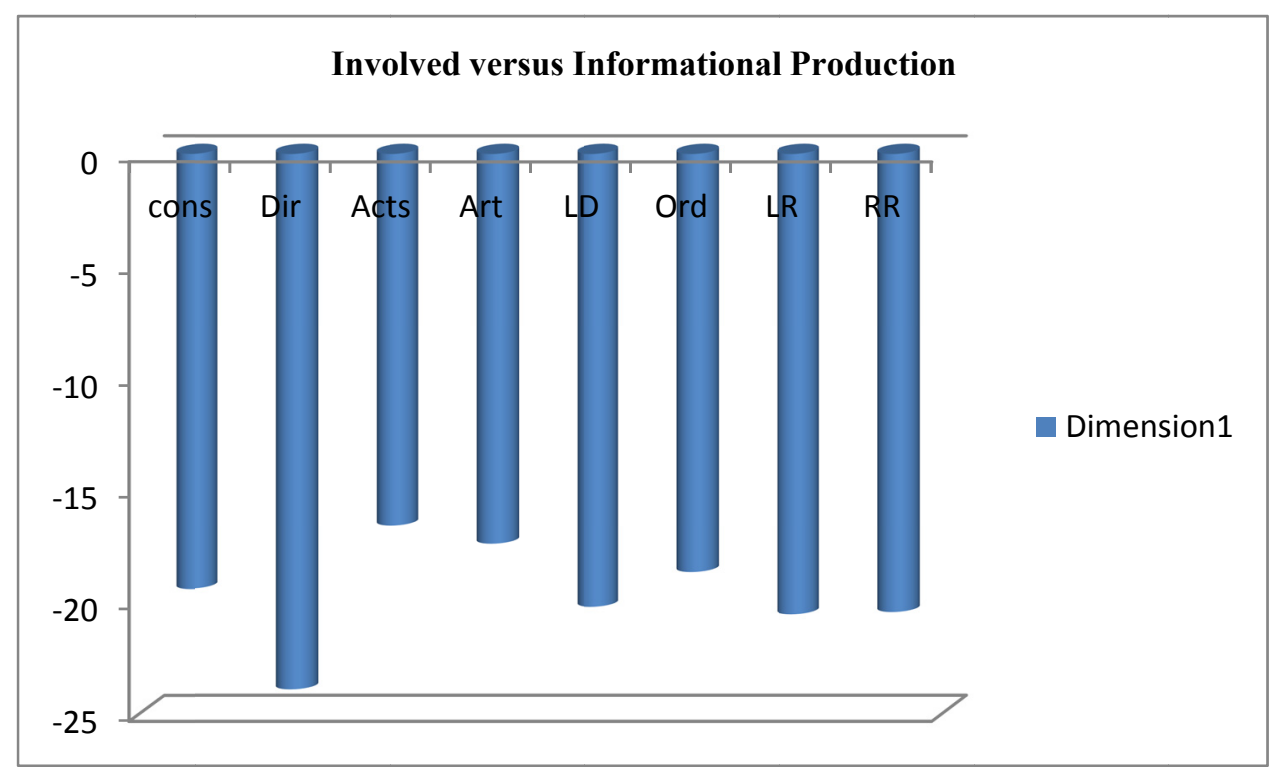

Figure 1. Comparison of legal genres along dimension 1 
The results of the comparison of Pakistani legal genres on dimension1 reveal that all legal genres i.e. constitutions, directives, acts, articles, legal decisions, ordinance, legal reports and rules and regulations are informational in nature and are marked with negative features in higher frequency. Those features include nouns, prepositions and adjectives. Though all of the legal genres are informational, but they vary in the level of information. Directives are the most informational of all whereas acts are least informational in comparison of other genres. Informational nature of these genres has been indicated by many scholars (Charrow \& Charrow, 1979; Gustafsson, 1975; Tiersma, 1999; Mattila, 2006; Roszkowski, 2011).

Following examples illustrates informational nature of Pakistani Legal English.

\section{Example: 1 Constitution}

World Environment Day, commemorated each year on 5th June, is one of the principal vehicles through which the United Nations stimulates worldwide awareness of the environment and enhances political attention and action.

\section{Example: 2 Acts}

The fund shall consist $\boldsymbol{o f}$,- donations and endowments; grants made $\boldsymbol{b y}$ the Federal Government; and any income accruing, to the Fund from its investments and property. The Fund shall be non-lapsable and may be maintained in Federal Treasury through personal ledger account lapsable on the 30th June of each year to Public Account under the head 3312026 Export Development Fund on the advice of Accountant General of Pakistan Revenues to Ministry of Commerce

\section{Dimension 2: Narrative versus Non- Narrative Concerns}

Dimension two marks the distinction between "Narrative vs. Non- narrative Concerns". This dimension comprises only positive features. These features include past tense forms, third person pronouns, perfect aspect verbs and public verbs.

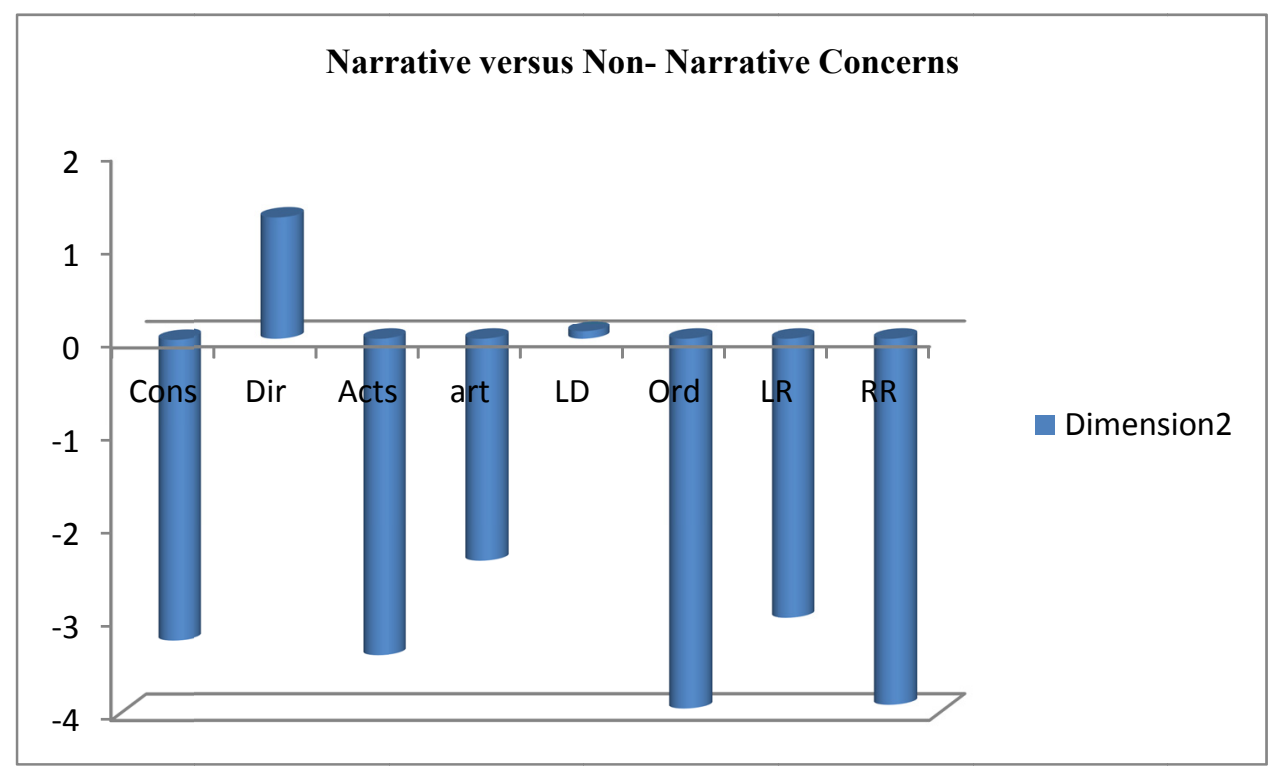

Figure 2. Comparison of legal genres along dimension 2

Comparison of legal genres on dimension 2 shows that narrative features are either very rare or absent in all legal genres. Most of the legal genres have negative scores which reflect that their primary concern is non-narrative. Ordinances, rules and regulations and constitutions are found highly non- narrative as compared to other legal genres. Ordinances have the highest negative scores (3.96) on this dimension. Only two genres, i.e. directives and legal decisions are concerned with narration, which shows that legal language is meant for sharing expository information which has "few verbs and few animate referents". Least narrative orientation, which is observed in legal decisions (0.08) is due to the reason that its one section comprises "procedural history, i.e. the facts of the case and how lower instance courts dealt with this case before it reached the appeal" (Roszkowski, 
2011, p. 155). Tendency of legal genres towards non-narrative concerns has also been reported by previous investigations (Ozyildirm, 2011; Roszkowski, 2011) conducted in Turkish and American contexts respectively.

Narrative concern in directives is evident through following example.

\section{Example: 3 Directive}

President General Pervez Musharraf reaffirmed on Monday that no compromise on national interests would be allowed. Addressing a group of editors and seniors columnists here at the Governor's House, he said there would be no roll back on 1 vital strategic assets of the country. $\boldsymbol{H e}$ reiterated that Government has so far taken no decision to send Pakistani troops to Iraq and neither it was under any pressure in this regard. However, he said the troops could be sent only under certain conditions already spelt out by the Government.

\section{Dimension 3: Explicit vs. Situation Dependent Reference}

Dimension three distinguishes between "Explicit Context Independent vs. Situation Dependent Discourse". Features with positive weight on this dimension include three different types of relative clauses, i.e. WH relative clauses on object position, WH relative clauses on subject position, WH relative clauses on the object position with prepositional fronting (pied piping), coordinating conjunction-phrasal connectors and nominalizations. These features collectively work as markers of explicit context independent informational text. On the other hand, features with negative weight on this dimension are: adverb of time, adverb of place and other adverbs. These features are associated with situation dependent discourse.

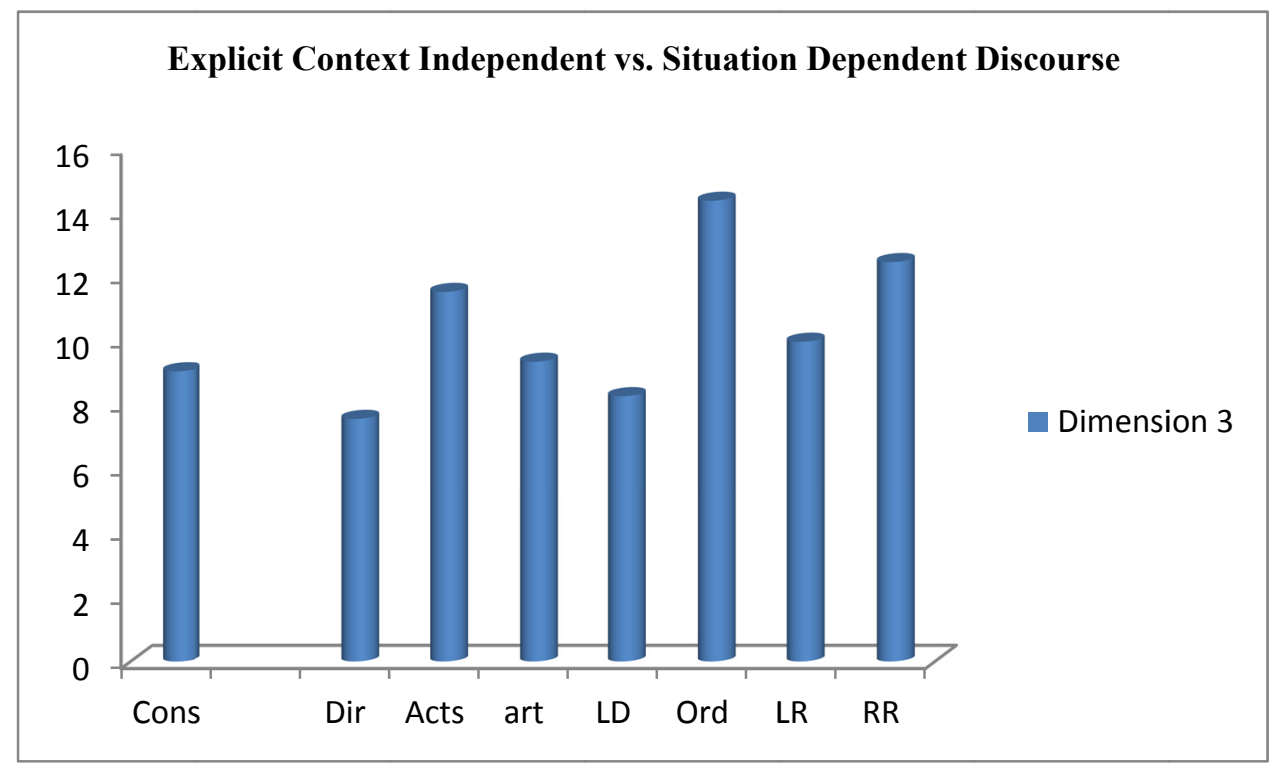

Figure 3. Comparison of legal genres along dimension 3

As is exhibited through the figure given above, all of the legal genres are elaborated and explicit instead of being context dependent. However, considerable variation is found across legal genres in this dimension too. Ordinances are the most elaborated (14.35). Lowest scores on this dimension (7.56, 8.25 respectively) are observed in directives and legal decisions. The findings of this dimension are also in line with the study of legal genres conducted in America (Roszkowski, 2011). This study also identifies all legal genres explicit and decontextualized, but in different degree from one another.

Following excerpt exhibits explicitness in legal text.

\section{Example 4. Ordinance}

WHEREAS it is expedient to establish on Export Processing Zones Authority for making all arrangements for the planning, development and management of the Zones and to provide for matters connected therewith "Industrial undertaking" means an industry, undertaking or establishment engaged in the production, distribution or processing of such goods or the providing of such services as may be specified in this behalf by the Federal Government; (f) "Investor" means a person or company investing in an industrial undertaking 
located in a Zone; "Manufacture" with its grammatical variations and cognate expressions, means the process of converting materials into a new product or article.

\section{Dimension 4: Overt Expression of Persuasion}

Dimension four consists of linguistic features having only positive weight. Features underlying this dimension are: infinitive verbs, modals of prediction, suasive verbs, subordinating conjunction-conditional, modals of necessity and adverbs within auxiliary (splitting auxiliary verbs). These features are associated with a persuasive style as is described by Biber (1988), "This dimension marks the degree to which persuasion is marked overtly, whether overt marking of the speaker's own point of view, or an assessment of the advisability or likelihood of an event presented to persuade the addresse" (p. 111).

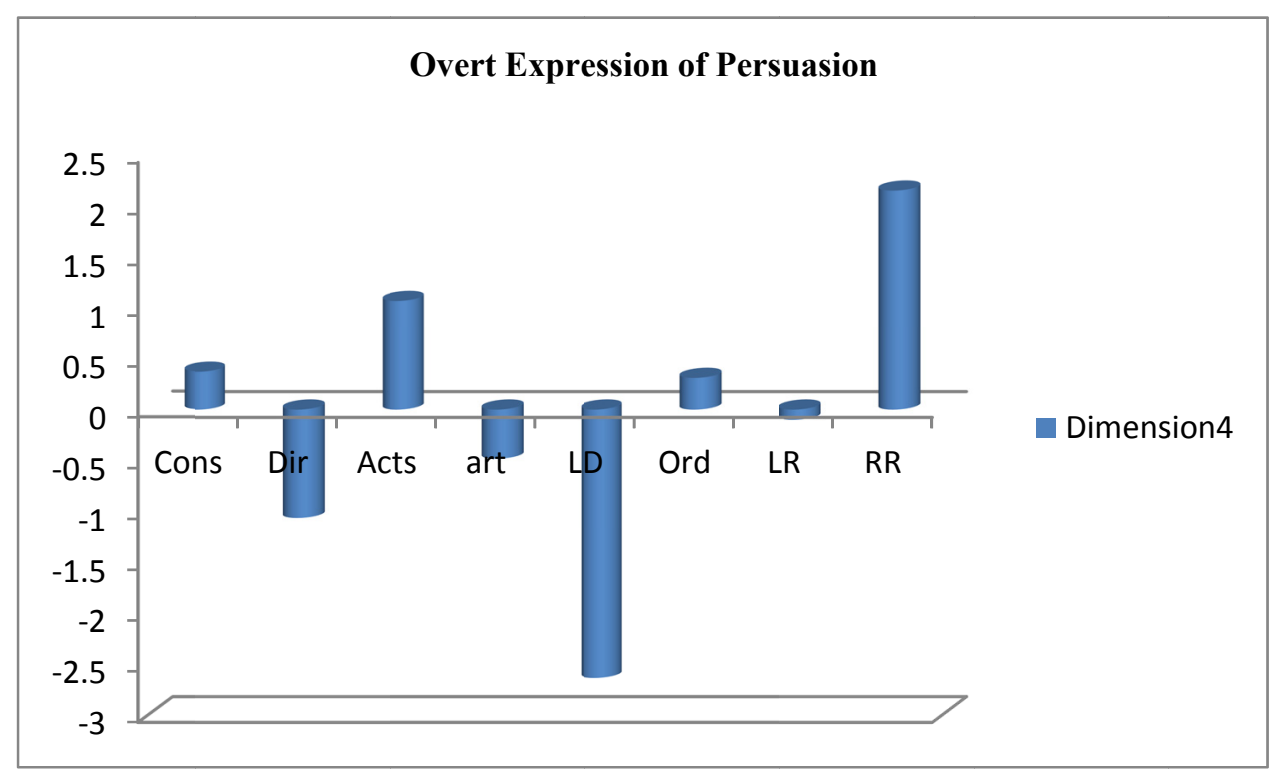

Figure 4. Comparison of legal genres along dimension 4

Dimension 4 having only positive features, has been discussed along a continuum scale instead of binary opposition. It reflects a clear split among legal genres. Constitutions, acts, ordinance and rules and regulations have positive weight on this dimension, whereas all other legal genres, i.e. directives, articles, legal decisions and legal reports have negative scores on this dimension. It indicates that constitutions, acts, ordinances and rules and regulations are persuasive in nature (though variation in degree of persuasion exists), whereas directives, articles, legal decisions and legal reports are unmarked on this dimension. Legal decisions have the highest negative scores on this dimension. It indicates their non- persuasive nature. Roszkowski (2011) also finds similar results in her study "Patterns of Linguistic Variation in American Legal English". She also identifies legal decisions on the negative pole on this dimension, thus showing non-argumentative concerns. But these findings are opposite to Tiersma (1999) who describes that legal decisions have persuasive elements in them.

Persuasive nature of legal English is evident in following example.

\section{Example 5. Act}

Whereas it is expedient to repeal and, with certain modifications, re-enact the law relating to legal practitioners and bar councils and to provide for certain incidental and ancillary matters: the employment of the legal practitioner in any legal business; or who proposes to any legal practitioner or to any person interested in any legal business to procure, in consideration of any remuneration moving from either of them. The Chief Justice shall declare who shall be taxing officer within the meaning of the first paragraph of this section. In all such suits the plaintiff shall state the amount at which he values the relief sought 14: Provided that nothing in this clause shall apply to suits mentioned in clause iv-A. 


\section{Dimension 5: Abstract vs. Non-Abstract Information}

Features on the positive pole on dimension five are: adverbial-conjuncts, agentless passive verbs, by passive, passive post nominal modifiers, subordinating conjunction other. These forms are associated with abstract and technical discourse with high formal style. No negative feature exists in this dimension.

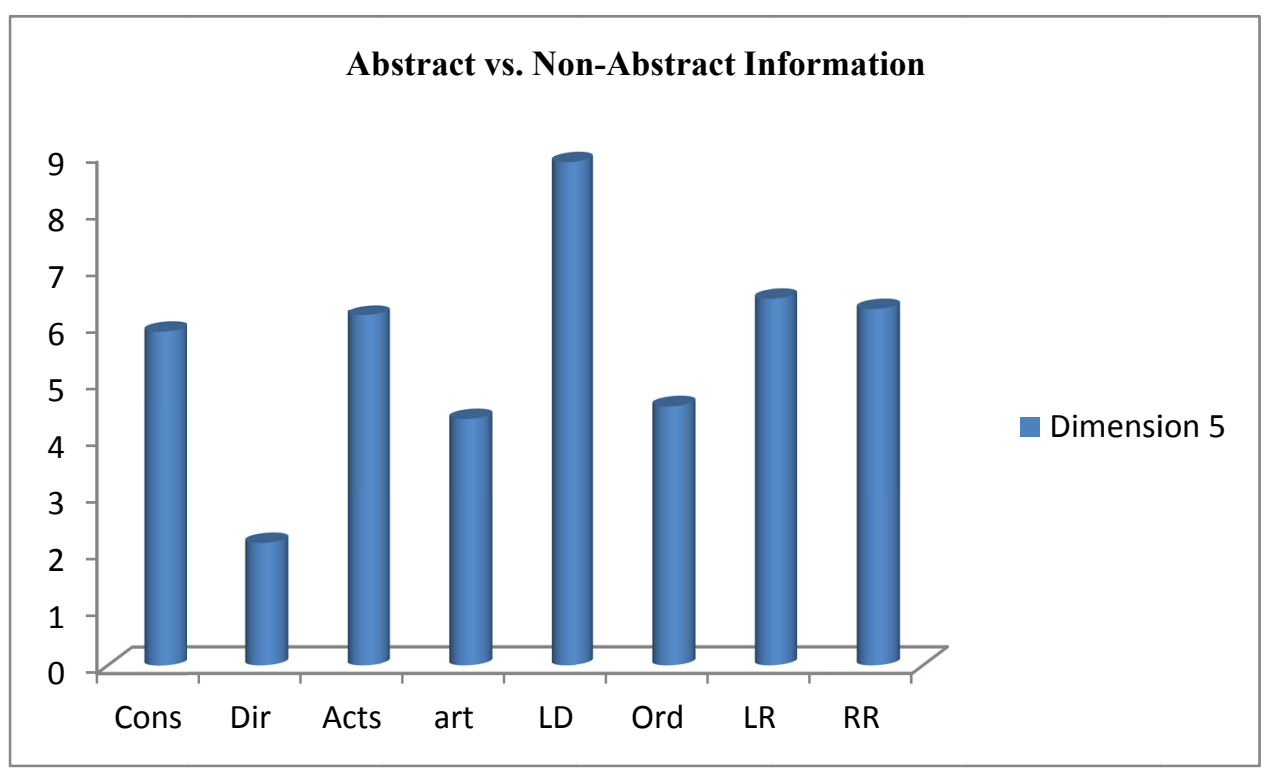

Figure 5. Comparison of legal genres along dimension 5

Dimension 5 is very significant as it speaks of the categorical distinction between technical and non- technical discourse, i.e. abstract and non-abstract information (the name originally given to this dimension by Biber (1988, p.152). Later on, this label was replaced with impersonal vs. non-impersonal style). Texts with positive scores on this dimension are impersonal and objective in style. The results of comparison among legal genres on this dimension indicate that all of the legal genres stand on the positive pole of this dimension, though variation exists among them in the level of abstraction. Legal decisions have the highest positive scores, whereas directives have the lowest positive scores. Findings (regarding the abstract nature of legal genres) support the perception that legal language is highly impersonal (Charrow \& Charrow, 1979; Tiersma, 1999; Alcaraz \& Hughes, 2002; Mellinkoff, 2004; Mattila, 2006). They also correspond to the results of the study by Roszkowski (2011) based on multidi mensional analysis of legal genres in American context. This study highlights that despite situational variations, all legal genres are impersonal and objective in style.

Following textual example illustrates objectivity in legal text.

\section{Example 6. Legal decision}

The State reported as 2006 MLD 1961 it has been held that when $20 \mathrm{Kg}$., Charas is recovered in the shape of Pattis and plates and only 250 grams was sent for chemical examination and when it was not mentioned whether the sample has been taken from each patti/plate then the punishment for entire lot cannot be provided. In another unreported judgment, dated 15-1-2007 in Criminal Bail Applicant No.633 of 2006.

\subsection{Analysis of Variance}

In order to see the significance level of difference among Pakistani legal genres, Analysis of variance has been applied. Legal genres have been considered significantly different if $p$-value is equal to or less than 0.05 .

Table 1. Comparison of legal genres along dimensions 1: involved vs. informational production

\begin{tabular}{lllll}
\hline Source of variation & Degrees of freedom & Sum of squares & Mean squares & F-value \\
\hline Category & 7 & 1127.21 & 161.03 & $14.95^{* *}$ \\
Error & 846 & 9111.22 & 10.77 & \\
Total & 853 & 10238.43 & & \\
\hline NS $=$ Non-significant $(\mathrm{P}>0.05) ; *$ Significant $(\mathrm{P}<0.05) ; * *$ highly significant $(\mathrm{P}<0.01)$.
\end{tabular}


Table 1 presents the results of comparison of legal genres (Constitutions, Directives, Acts, Articles, Legal Decisions, Ordinance, Legal Reports, Rules and Regulations) along dimension one: Involved vs. Informational Production. The results reveal that there is a highly significant difference $(F=14.95, \mathrm{P}<0.01)$ among categories on this dimension. Though all of them are informational (as is indicated in ch.4 section 1), yet there is a difference in density of information packed in these categories.

Table 2. Comparison of legal genres along dimensions 2 of 88 model of variation

\begin{tabular}{lllll}
\hline Source of variation & Degrees of freedom & Sum of squares & Mean squares & F-value \\
\hline Category & 7 & 1576.93 & 225.28 & $76.81^{* *}$ \\
Error & 846 & 2481.37 & 2.93 & \\
Total & 853 & 4058.30 & & \\
\hline
\end{tabular}

Note. $\mathrm{NS}=$ Non-significant $(\mathrm{P}>0.05) ; *=$ Significant $(\mathrm{P}<0.05) ; * *=$ highly significant $(\mathrm{P}<0.01)$.

Table 2 shows the result of comparison among legal genres along dimension 2 labelled as "Narrative vs. NonNarrative Concerns". Results reveal that all legal genres (Constitutions, Directives, Acts, Articles, Legal Decisions, Ordinance, Legal Reports, Rules and Regulations) significantly differ from one another $(F=76.80$, $\mathrm{P}<0.01)$ ). The significant $\mathrm{F}$ score indicates that means of categories are not equal and there is greater variation among groups than within groups.

Table 3. Comparison of legal genres along dimensions 3 of 88 model of variation

\begin{tabular}{lllll}
\hline Source of variation & Degrees of freedom & Sum of squares & Mean squares & F-value \\
\hline Category & 7 & 1187.90 & 169.70 & $27.13^{* *}$ \\
Error & 846 & 5292.48 & 6.26 & \\
Total & 853 & 6480.38 & & \\
\hline
\end{tabular}

Note. NS $=$ Non-significant $(\mathrm{P}>0.05) ; *=$ Significant $(\mathrm{P}<0.05) ; * *$ highly significant $(\mathrm{P}<0.01)$.

Table 3 exhibits the results of comparison among legal genres along dimension 3: "Explicit vs. Situation Dependent Reference". The results show a highly significant difference $(F=27.13, P<0.01)$ among categories of legal genres.

Table 4. Comparison of legal genres along dimensions 4 of 88 model of variation

\begin{tabular}{lllll}
\hline Source of variation & Degrees of freedom & Sum of squares & Mean squares & F-value \\
\hline Category & 7 & 1334.71 & 190.67 & $51.70^{* *}$ \\
Error & 846 & 3120.13 & 3.69 & \\
Total & 853 & 4454.84 & & \\
\hline
\end{tabular}

Note. $\mathrm{NS}=$ Non-significant $(\mathrm{P}>0.05) ; *=$ Significant $(\mathrm{P}<0.05) ; * *$ highly significant $(\mathrm{P}<0.01)$.

Table 4 displays the results of ANOVA, which has been conducted to find out differences among legal genres (Constitutions, Directives, Acts, Articles, Legal Decisions, Ordinance, Legal Reports, Rules and Regulations) along dimension four labelled as "Overt Expression of Persuasion". The results reveal highly significant variability $(F=51.70, \mathrm{P}<0.01)$ among legal genres along this dimension. As the $F$ score is high, it shows that difference between legal genres is greater than within genres.

Table 5. Comparison of Legal Genres along Dimensions 5 of 88 Model of Variation

\begin{tabular}{llcc}
\hline Source of variation & Degrees of freedom & Sum of squares & Mean squares \\
\hline Category & 7 & 2702.96 & 386.14 \\
Error & 846 & 7932.36 & 9.38 \\
Total & 853 & 10635.32 & $41.18^{* *}$ \\
\hline Note NS = Non-significant $(\mathrm{P}>0.05) ; *$ Significant $(\mathrm{P}<0.05) ; * *=$ highly significant $(\mathrm{P}<0.01)$.
\end{tabular}


Table 5 shows the comparison of legal genres (Constitutions, Directives, Acts, Articles, Legal Decisions, Ordinance, Legal Reports, Rules and Regulations) along dimension 5 labeled as "Impersonal vs. Non-impersonal Style". The results show statistically highly significant difference $(\mathrm{F}=41.18, \mathrm{P}<0.01)$ among legal genres. The following section presents multiple comparisons among legal genres to indicate the point of difference in them.

\subsection{Multiple Comparisons}

ANOVA results have identified statistically significant difference among categories of legal genres along each dimension, but have not pointed out the differences among genres on an individual basis. For this purpose, Multiple Comparisons have been applied.

Following table demonstrates the difference in legal genres on an individual basis.

Table 6. Comparison of Mean \pm SE along dimension 1

\begin{tabular}{ll}
\hline Category & Mean $\pm \mathrm{SE}$ \\
\hline Constitutions & $-19.44 \pm 1.518 \mathrm{BCD}$ \\
Directives & $-23.93 \pm 1.564 \mathrm{E}$ \\
Acts & $-16.61 \pm 1.036 \mathrm{~A}$ \\
Articles & $-17.45 \pm 0.530 \mathrm{AB}$ \\
Legal Decisions & $-20.26 \pm 0.110 \mathrm{CD}$ \\
Ordinance & $-18.71 \pm 0.797 \mathrm{ABC}$ \\
Legal Reports & $-20.59 \pm 0.397 \mathrm{D}$ \\
Rules and regulations & $-20.49 \pm 0.644 \mathrm{CD}$ \\
\hline
\end{tabular}

Note. Means sharing similar letters are statistically non-significant $(\mathrm{P}>0.05)$.

Table 6 shows comparison of each legal genre with other legal genres on individual basis. It reveals that constitutions are not significantly different from articles, legal decisions, ordinances, legal reports and rules and regulations whereas they vary significantly from other legal genres i.e. directives and acts.

Directives are found statistically significantly different from all other legal genres. In case of acts, significant difference has been observed among this genre and constitutions, directives, legal decisions, legal reports and rules and regulations. Besides this, articles have been identified statistically significantly different from other genres i.e. directives, legal decisions, legal reports and rules and regulations. Legal decisions are significantly different with directives, acts and articles. Ordinances' difference with directives and legal reports is statistically significant. As regards legal reports, they are significantly different from directives, acts, articles and ordinances whereas genre of rules and regulations varies significantly from directives, acts and articles.

Table 7. Comparison of Mean \pm SE along dimension 2

\begin{tabular}{ll}
\hline Category & Mean $\pm \mathrm{SE}$ \\
\hline Constitutions & $-3.23 \pm 0.276 \mathrm{BC}$ \\
Directives & $1.31 \pm 1.246 \mathrm{~A}$ \\
Acts & $-3.39 \pm 0.253 \mathrm{BC}$ \\
Articles & $-2.38 \pm 0.128 \mathrm{~B}$ \\
Legal Decisions & $0.08 \pm 0.072 \mathrm{~A}$ \\
Ordinance & $-3.96 \pm 0.149 \mathrm{C}$ \\
Legal Reports & $-2.99 \pm 0.147 \mathrm{BC}$ \\
Rules and regulations & $-3.92 \pm 0.136 \mathrm{C}$ \\
\hline
\end{tabular}

Note. Means sharing similar letters are statistically non-significant $(\mathrm{P}>0.05)$.

Table 7 indicates that constitutions, acts and articles are significantly different from directives and legal decisions whereas their difference with each other and other legal genres is statistically non- significant. Directives and legal decisions' means do not share similar letters with other legal genres which indicates statistically non-dignificant difference among them and other legal genres i.e. constitutions, acts, articles, ordinances, legal reports and rules and regulations. Articles have been found significantly different from directives, legal decisions, ordinances and rules and regulations. So far as ordinances and rules and regulations are concerned, they reveal significant difference from directives, articles and legal decisions. 
Table 8. Comparison of Mean \pm SE along dimension 3

\begin{tabular}{ll}
\hline Category & Mean \pm SE \\
\hline Constitutions & $9.04 \pm 1.281 \mathrm{CD}$ \\
Directives & $7.56 \pm 1.407 \mathrm{D}$ \\
Acts & $11.52 \pm 0.342 \mathrm{~B}$ \\
Articles & $9.32 \pm 0.249 \mathrm{C}$ \\
Legal Decisions & $8.25 \pm 0.097 \mathrm{D}$ \\
Ordinance & $14.35 \pm 0.545 \mathrm{~A}$ \\
Legal Reports & $9.94 \pm 0.349 \mathrm{C}$ \\
Rules and regulations & $12.45 \pm 0.566 \mathrm{~B}$ \\
\hline
\end{tabular}

Note. Means sharing similar letters are statistically non-significant $(\mathrm{P}>0.05)$.

Table 8 demonstrates the results of multiple comparison on dimension 3. Constitutions differ significantly from acts, ordinances and rules and regulations whereas directives vary significantly from acts, articles, ordinances, legal reports and rules and regulations. Acts and rules and regulations have been noted different from constitutions, directives, articles, legal decisions, ordinances and legal reports and this difference is statistically significant. Articles and legal reports are statistically significantly different from directives, acts, legal decisions, ordinances and rules and regulations. In case of legal decisions, significant difference has been shown between this genre and other legal genres i.e. acts, articles, ordinances, legal reports and rules and regulations. Ordinances have also been found significantly different from constitutions, directives, acts, articles, legal decisions, legal reports and rules and regulations.

Table 9. Comparison of Mean \pm SE along dimension 4

\begin{tabular}{ll}
\hline Category & Mean $\pm \mathrm{SE}$ \\
\hline Constitutions & $0.37 \pm 1.015 \mathrm{BC}$ \\
Directives & $-1.06 \pm 0.825 \mathrm{C}$ \\
Acts & $1.07 \pm 0.407 \mathrm{AB}$ \\
Articles & $-0.48 \pm 0.308 \mathrm{C}$ \\
Legal Decisions & $-2.64 \pm 0.064 \mathrm{D}$ \\
Ordinance & $0.31 \pm 0.453 \mathrm{BC}$ \\
Legal Reports & $-0.10 \pm 0.284 \mathrm{C}$ \\
Rules and regulations & $2.15 \pm 0.355 \mathrm{~A}$ \\
\hline
\end{tabular}

Note. Means sharing similar letters are statistically non-significant $(\mathrm{P}>0.05)$.

Results of multiples comparison on dimension 4 exhibit significant difference of constitutions and ordinances with legal decisions and rules and regulations. Directives, articles and legal reports are significantly different from acts, legal decisions and rules and regulations. Acts vary significantly from directives, articles, legal decisions, legal reports whereas legal decisions' difference with constitutions, directives, acts, articles, ordinances, legal reports and rules and regulations is statistically significant. A significant variation has also been observed among rules and regulations and constitutions, directives, articles, legal decisions, ordinances and legal reports.

Table 10. Comparison of Mean \pm SE along dimension 5

\begin{tabular}{ll}
\hline Category & Mean $\pm \mathrm{SE}$ \\
\hline Constitutions & $5.88 \pm 0.933 \mathrm{BCD}$ \\
Directives & $2.14 \pm 0.898 \mathrm{E}$ \\
Acts & $6.17 \pm 0.547 \mathrm{BC}$ \\
Articles & $4.34 \pm 0.284 \mathrm{D}$ \\
Legal Decisions & $8.86 \pm 0.129 \mathrm{~A}$ \\
Ordinance & $4.56 \pm 0.389 \mathrm{CD}$ \\
Legal Reports & $6.47 \pm 0.323 \mathrm{~B}$ \\
Rules and regulations & $6.29 \pm 0.535 \mathrm{BC}$ \\
\hline
\end{tabular}

Note. Means sharing similar letters are statistically non-significant $(\mathrm{P}>0.05)$. 
Table 10 presents results of multiple comparison on dimension 5. It shows significant difference among constitutions and two other legal genres (directive and legal decisions). Directives and legal decisions have been found significantly different from all other legal genres mentioned above. Acts and rules and regulations have also been noted different from directives, articles and legal decisions and this difference is statistically significant. As regards articles, significant variation has been observed among this genre and sirectives, acts, legal decisions, legal reports and rules and regulations. Ordinances differ significantly from legal reports, legal decisions and directives while legal reports have shown significant difference from directives, articles, legal decisions and ordinances.

Tables 6 to 10 have illustrated the results of multiple comparisons of legal genres along five dimensions. The comparison shows that the most of the legal genres vary from one another along each dimension which supports the idea of variation within register.

It shows that legal discourse is not a monolithic phenomenon; differences among legal genres depend upon their context of use.

\section{Conclusions}

The findings of the study lead to following conclusions:

From the comparison of legal genres along 1988 model of variation, it turns out that all genres are informational though significant variation in informational level exists. Almost all of them are non-narrative. Only directives and legal decisions have least concern for narrative orientations. All of them have the tendency towards elaboration and explicitness and have a little tendency towards situation dependent discourse. Besides, most of them are marked with least persuasion and all of them are impersonal and objective in the information they impart. However, a considerable variation is found among legal genres in the degree to which they have these characteristics. The distribution of the mean scores of legal genres on each dimension shows remarkable differences within legal discourse. In point of fact, regular patterns can be observed in dimension 1,3 and dimension5 where all legal genres fall on the same pole either positive or negative. Dimension 2 and dimension4 split legal genres in both of the poles. On dimension 2, directives have positive scores, but scores of legal decisions have around zero mean score and all other genres have negative scores thus non-narrative. Dimension 4 shows, acts and rules and regulations clearly on the positive pole while other genres have negative weight. This variation among legal genres is described by Mattila (2006), there are different subgenres within legal language and each has particular characteristics. This indicates different purpose of their communication and conforms to the notion of register studies that lexico-grammatical features are distributed differently in different genres or textual categories. Reason for this difference is stated by Lemke (1995), with the difference in the field of activity, frequencies of lexico-grammatical patterns change which indicate changes in communicative purpose.

This study concludes that term legal discourse is a misnomer. In fact, there are legal discourses found across different legal genres.

\section{References}

Ahmad, S. (2015). Linguistic Variation Across Press Reportage in Pakistani Print media: A Multidimensional Analysis. Unpublished Ph.D. dissertation, Govt. College University Faisalabad.

Ahmed, N. (2005). Legal English; A case for ESP. Doctoral dissertation, Bahauddin Zakariya University, Multan.

Alcarazz, A., \& Hughes, B. (2002). Legal translation explained. Manchester: St. Jerome Publishing.

Ali, S. A. (2016). Multidimensional Analysis of Pakistani English Fiction. Unpublished Ph.D. dissertation, Govt. College University Faisalabad.

Alvi, U. F., \& Mahmood, M. A. (2016). A Multidimensional Analysis of Pakistani Press Editorials. The Dialogue, 11(284), 3270-284.

Bhatia, V. K. (1987). Textual-Mapping in British Legislative Writing. World Englishes, 6, 1-10. https://doi.org/10.1111/j.1467-971X.1987.tb00172.x

Bhatia, V. K. (1993). Analysing Genre: Language Use in Professional Settings (p. 5). London: Longman.

Biber, D. (1988). Variation Across Speech and Writing. Cambridge: Cambridge University Press.

Brown, P., \& Fraser, C. (1979). Speech as a marker of situation. In K. R. Scherer \& H. Giles (Eds), Social markers in speech (pp. 33-62). Cambridge University Press. 
Charrow, R. P., \& Charrow, V. R. (1979). Making legal language understandable: A psycholinguistic study of jury instructions. Columbia law review, 79(7), 1306-1374. https://doi.org/10.2307/1121842

Conrad, S., \& Biber, D. (2001). Multi-dimensional methodology and the dimensions of register variation in English. In S. Conrad \& D. Biber (Eds.), Variation in English: multi-dimensional studies (pp. 13-42). Pearson: Harlow, UK.

Danet, B. (1983). Studies in legal discourse (pp. 440-500). Special Edition of Text 4.

Danet, B. (1985). Legal Discourse. In T. A. Van Dijk (Ed.), Handbook of Discourse Analysis 1. London: Academic Press.

Gibbons, J. (2004). Taking legal language seriously. In J. Gibbons, V. Prakasam, K. V. Tirumalesh, \& N. Hemalatha (Eds.), Language and the Law (pp. 2-20). New Delhi: Orient Longman.

Gotti, M. (2001). Semantic and pragmatic values of shall and will in Early Modern English statutes. Modality in Specialized Texts (pp. 89-111). Bern: Peter Lang.

Gotti, M. (2008). Investigating specialized discourse. Peter Lang.

Gustafsson, M. (1975). Some syntactic properties of English law language. Publication of the Department of English 4, Turku, University of Turku.

Jackson, B. S. (1995). Making Sense in Law. Deborah Charles Publications, Liverpool.

Khan, R. B., \& Khan, S. Q. (2015). Stylistic study of legal language. International Journal of Engineering Research and General Science, 3(1).

Lemke, J. L. (1995) Textual politics: discourse and social dynamics (p. 27). London: Taylor and Francis.

Maley, Y. (1994). The language of the law. In J. Gibbons (Ed.), Language and the Law (pp. 11-50). New York: Longman.

Mattila, H. E. S. (2006). Comparative legal linguistics. Hampshire: Ashgate Publishing.

Mellinkoff, D. (2004). The language of the law. Wipf and Stock Publishers.

Özyildirim, I. A. (2011). Comparative Register Perspective on Turkish Legislative Language. Scientific Research Division, Ankara.

Palmer, J., \&.Pearce, F. (1983). Legal discourse and state power-foucault and the juridical relation. International Journal of the Sociology of law, 11(4), 361-383.

Roszkowski, G. S. (2011). Lodz Studies in Language: Patterns of Linguistic Variation in American Legal English: A Corpus-Based Study. Frankfurt am Main, DE: Peter Lang GmbH, Internationaler Verlag der Wissenschaften.

Shakir, A. (2013). Linguistic variation across print advertisements in Pakistani media: A multidimensional analysis. Unpublished doctoral dissertation, International Islamic University, Islamabad.

Tiersma, P. (1999). Legal Language. Chicago: University of Chicago Press.

Trosborg, A. (1995). Interlanguage pragmatics: Requests, complaints, and apologies (Vol. 7). Walter de Gruyter.

Trosborg, A. (1997). Text typology and translation (Vol. 26). John Benjamins Publishing.

\section{Appendix}

\section{Descriptive Statistics of Dimensions for all Legal Genres}

\section{Constitutions}

\begin{tabular}{llllll}
\hline & Mean & Minimum Value & MaximumValue & Range & Standard Deviation \\
\hline Dimension1 & -19.44 & -25.83 & -10.96 & 14.87 & 4.55 \\
Dimension2 & -3.23 & -4.27 & -1.61 & 2.66 & 0.83 \\
Dimension3 & 9.04 & 2.25 & 13.24 & 10.99 & 3.84 \\
Dimension4 & 0.37 & -4.14 & 5.47 & 9.61 & 3.05 \\
Dimension5 & 5.88 & 2.56 & 11.06 & 8.5 & 2.8 \\
\hline
\end{tabular}


Directives

\begin{tabular}{llllll}
\hline & Mean & MinimumValue & MaximumValue & Range & Standard Deviation \\
\hline Dimension 1 & -23.93 & -33.14 & -13.97 & 19.17 & 5.64 \\
Dimension2 & 1.31 & -4.36 & 11.43 & 15.79 & 4.49 \\
Dimension3 & 7.56 & -0.58 & 17.42 & 18 & 5.07 \\
Dimension4 & -1.06 & -6.61 & 2.9 & 9.51 & 2.98 \\
Dimension5 & 2.14 & -3.63 & 7.14 & 10.77 & 3.24 \\
\hline
\end{tabular}

Acts

\begin{tabular}{lllllc}
\hline & Mean & MinimumValue & MaximumValue & Range & Standard Deviation \\
\hline Dimension 1 & -16.61 & -24.04 & -7.65 & 16.39 & 4.14 \\
Dimension2 & -3.39 & -4.82 & -1.14 & 3.68 & 1.01 \\
Dimension3 & 11.52 & 8.99 & 13.48 & 4.49 & 1.37 \\
Dimension4 & 1.07 & -1.62 & 3.91 & 5.53 & 1.63 \\
Dimension5 & 6.17 & 1.69 & 8.95 & 7.26 & 2.19 \\
\hline
\end{tabular}

\section{Articles}

\begin{tabular}{llllll}
\hline & Mean & Minimum Value & MaximumValue & Range & Standard Deviation \\
\hline Dimension 1 & -17.45 & -33.22 & -5.17 & 28.05 & 5.3 \\
Dimension2 & -2.38 & -4.6 & 2.7 & 7.3 & 1.28 \\
Dimension3 & 9.32 & 2.68 & 17.02 & 14.34 & 2.49 \\
Dimension4 & -0.48 & -5.67 & 13.2 & 18.87 & 3.08 \\
Dimension5 & 4.34 & -2.2 & 10.12 & 12.32 & 2.84 \\
\hline
\end{tabular}

\section{Legal Decisions}

\begin{tabular}{llllll}
\hline & Mean & Minimum Value & MaximumValue & Range & Standard Deviation \\
\hline Dimension 1 & -20.26 & -26.62 & -6.52 & 20.1 & 2.74 \\
Dimension2 & 0.08 & -4.13 & 7.11 & 11.24 & 1.78 \\
Dimension3 & 8.25 & 0.84 & 17.25 & 16.41 & 2.41 \\
Dimension4 & -2.64 & -6.61 & 4.09 & 10.7 & 1.6 \\
Dimension5 & 8.86 & 1.55 & 25.09 & 23.54 & 3.21 \\
\hline
\end{tabular}

\section{Ordinances}

\begin{tabular}{llllll}
\hline & Mean & Minimum Value & Maximum Value & Range & Standard Deviation \\
\hline Dimension 1 & -18.71 & -24.68 & -14.22 & 10.46 & 3.19 \\
Dimension2 & -3.96 & -4.77 & -2.47 & 2.3 & 0.6 \\
Dimension3 & 14.35 & 10.03 & 17.34 & 7.31 & 2.18 \\
Dimension4 & 0.31 & -3.62 & 3.93 & 7.55 & 1.81 \\
Dimension5 & 4.56 & 1.79 & 6.79 & 5 & 1.56 \\
\hline
\end{tabular}

\section{Legal Reports}

\begin{tabular}{llllll}
\hline & Mean & Minimum Value & Maximum Value & Range & Standard Deviation \\
\hline Dimension1 & -20.59 & -29.7 & -13.66 & 16.04 & 3.08 \\
Dimension2 & -2.99 & -5.22 & 0.85 & 6.07 & 1.14 \\
Dimension3 & 9.94 & 5.13 & 19.66 & 14.53 & 2.71 \\
Dimension4 & -0.1 & -3.53 & 6.05 & 9.58 & 2.2 \\
Dimension5 & 6.47 & 1.48 & 11.76 & 10.28 & 2.5 \\
\hline
\end{tabular}

\section{Rules and Regulations}

\begin{tabular}{llllll}
\hline & Mean & Minimum Value & MaximumValue & Range & Standard Deviation \\
\hline Dimension1 & -20.49 & -26.14 & -14.57 & 11.57 & 2.88 \\
Dimension2 & -3.92 & -4.8 & -2.69 & 2.11 & 0.61 \\
Dimension3 & 12.45 & 7.29 & 16.09 & 8.8 & 2.53 \\
Dimension4 & 2.15 & -0.61 & 5.01 & 5.62 & 1.59 \\
Dimension5 & 6.29 & 0.75 & 10.68 & 9.93 & 2.39 \\
\hline
\end{tabular}




\section{Copyrights}

Copyright for this article is retained by the author, with first publication rights granted to the journal.

This is an open-access article distributed under the terms and conditions of the Creative Commons Attribution license (http://creativecommons.org/licenses/by/4.0/). 